\title{
Planning the development of spatial management and transport system of a city from the point of view of environmental impact
}

\author{
Jacek Chmielewski, and Tomasz Szczuraszek* \\ University of Science and Technology, Department of Traffic Engineering and Transport, 85-796 \\ Bydgoszcz, Kaliskiego 7, Poland
}

\begin{abstract}
Summary. This paper presents the results of analyses of the influence of changes in spatial management on changes in the emissions of selected harmful chemicals and road traffic noise. The analyses were carried out for different scenarios of urban development: from a compact city with densely developed areas and a higher residential density to a diffuse city, where residents live in suburban areas with good quality of air, but have to spend a lot of time commuting to work and school. The results of traffic modelling analyses considering transport needs of a specific urban area enabled the determination of possible effects of a spatial planning policy on the residents' standard of living and the influence of the policy on natural environment. The article ends with conclusions and recommendations for planning the development of a city's spatial management from the point of view of the transport needs of its residents and the impact of their everyday trips on the environment.
\end{abstract}

\section{Introduction}

Spatial management of an area - and an urban area in particular - has a direct effect on the transport needs of its residents and the way of satisfying them. At the same time, transport systems designed to satisfy such needs as well as the transport requirements of different industries and business sectors substantially influence the approach to spatial management. This is because an increased degree of urbanisation drives the development of transport systems. Well-developed transport systems effectively stimulate the development of housing, trade and industry. Thus, there is a strict correlation between spatial management and transport systems. Transport systems - including but not only car-related - have a substantial effect on the residents' standard of living and the quality of life, often represented by the quality of air and traffic noise.

Political and economic transformations in Poland and especially the accession of the country to the EU have caused a number of major social and economic changes. EU grants, largely aimed to improve transport infrastructure, have substantially influenced the labour market. Long-term investments in economy, including transport systems, have made it possible to reduce unemployment and contributed to an increase in the overall wealth of the

\footnotetext{
${ }^{*}$ Corresponding author: jacek-ch@utp.edu.pl
} 
population. Even the time of the world economic crisis of 2007-2009, which hit the USA and Great Britain the most, only caused a slowdown in the economic development in Poland [1]. With a continuous growth in GDP observed at the time [2], the country was seen as a 'green island' in terms of economic situation. As a result, since 1990s we have witnessed a gradual increase in the affluence of the Polish society, bringing about such effects as:

1. A steep rise in the motorisation rate, causing increased number of trips in private vehicles;

2. Increased mobility of the population, defined as the number of trips made in a 24-hour period covering a distance of more than $50 \mathrm{~m}$ from the point of origin to the destination; the availability of a comfortable means of transport (own vehicle) enabling door-to-door travel makes people more mobile and increases the number of trips [3];

3. Changing places of residence as a result of internal migration of the increasingly affluent society looking for home far from city noise, industries and excessive air pollution and choosing suburban areas: green, quiet and clean.

Another trend observed in Poland is a dramatic drop in fertility rates [4]. From the year 1984 the fertility rate was steadily falling from 2.14 births per woman to 1.22 in 2003 . In spite of a number of measures undertaken by the government to improve the rate, the current figure is 1.32 births per woman, which puts Poland in $212^{\text {th }}$ place globally, below Germany, Hungary, Great Britain or Greece, to name a few. As a result, the society is evidently ageing and this leads to changes in travel behaviours. Unfortunately, the ageing process - in the long run - will cause a substantial decrease in the population number, which is already observed in Polish and European cities [5].

In view of the above considerations, the authorities of medium-sized and large cities, for which the residents are a source of revenues from taxes, undertake series of measures to reverse the trends. This applies in particular to internal migration patterns [6]. A lot of residents leave the cities to settle in the suburbs where the costs of land or a house, and taxes are generally smaller. Those areas usually offer better living conditions, quality of air, proximity of green spaces, a much lower population density and traffic nuisance. Therefore, they seem to be more attractive to set up home both to young people and the elderly, looking for peace and quiet. In order to halt the unfavourable tendency the authorities seek competitive alternatives to the suburbs, offering advantageous conditions of settlement in urban areas, sometimes located quite far from the city centre. One of such advantages providing a competitive edge over suburban areas is the accessibility of public transport whose quality of service is often higher than the one encountered in the suburbs.

Questions therefore arise about the consequences of such measures: to what extent do the urban residential areas, distant from the centre, endorsed by the authorities actually serve the purpose of a proper development of the city? How much do the effects of such a spatial management policy influence the living conditions of the residents, including in particular their health, and the aspects of environmental protection?

\section{Research methodology}

Considering the research methodology which would enable the determination of the influence of changes in spatial management of an area on its residents' quality and comfort of life, and on the local environment, the availability of reliable data for analysis should be taken into account. One possible approach is to compare different scenarios of changes in spatial management of a given area. The purpose is here to study the influence of modification in the object of observation on the course of the studied phenomenon. The 
observation concerns the data which describes functional parameters of transport systems and the emission of elementary chemical pollutants and noise.

The mathematical tool was provided by a simulation transport model, developed on the basis of field research into the operation of transport systems and surveys regarding travel behaviours of the residents of a selected test site, conducted in 2016. The test site was a medium-sized Polish city with a surface area of $176 \mathrm{~km}^{2}$ and more than 350,000 inhabitants, with a population density exceeding 2,000 people per $\mathrm{km}^{2}$. The city has $35 \%$ of green spaces and less than $19 \%$ of farmland. The applied simulation transport model is based on two layers: the supply layer (transport systems available within the analysed area) and the demand layer (transport needs of the residents), as well as mathematical procedures to perform simulation calculations of the mutual correlations between the two layers (Fig. $1)$.

The demand layer is described by a directed graph $G$, representing the infrastructure of transport systems available in the area under consideration, defined as follows:

$$
G=<W, L>
$$

where $W$ : describes the points (graph nodes),

$L$ : describes the lines (graph arcs) in the following form:

$$
L=\left\{(i, j): \eta_{i j}=1, i \neq j, i, j \in W\right\}
$$

and

$$
\eta=W \times W \rightarrow\{0,1\}
$$

however $\eta(i, j)=1$ only if between the nodes $i$ and $j$ there is a transport link.

The point set comprises the places where the trip begins and ends, and the places of mutual intersection and correlation of the transport systems. The line set is described by available transportation routes used to make the trip, and their performance characteristics (length, flow capacity, speed of travel within the transport system, costs etc.).

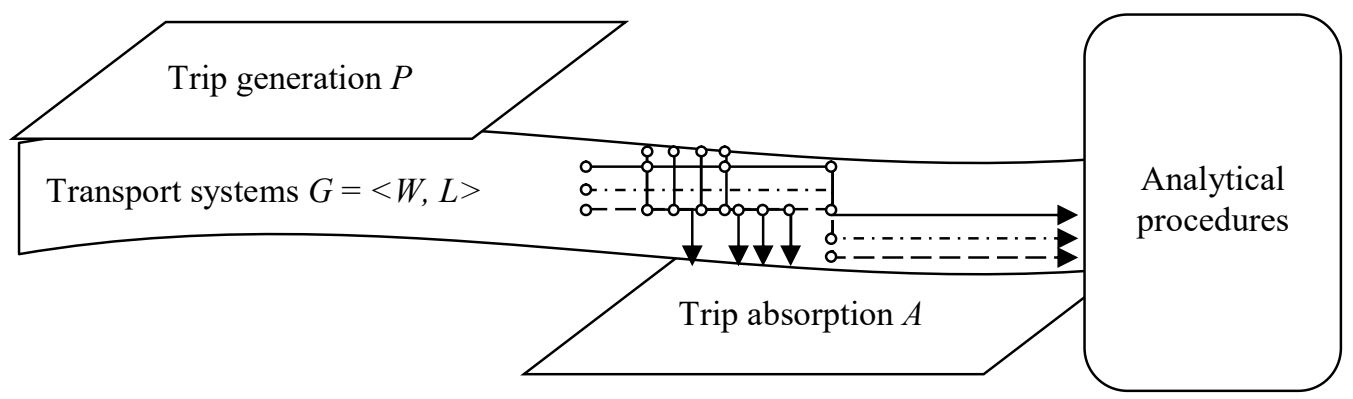

Fig. 1. Schematic diagram of the transport model

The demand layer is described by trip generation, $P$ :

$$
P=<p: e_{1}(p)=1, p \in W>
$$

where if $e_{1}(p)=1$, then node $p$ is the initial trip point, or else if $e_{1}(p)=0$, and trip absorption, $A$ :

$$
A=<a: e_{2}(a)=1, a \in W>
$$

where if $e_{2}(a)=1$, then node $a$ is the terminal trip point, or else $e_{2}(a)=0$. 
Both elements are represented by areas called traffic zones, which make the origins and destination of trips, and the number of trips between them are by means of a matrix calculus using the so-called trip matrix in the Cartesian product:

$$
e: P \times A \rightarrow\{0,1\}
$$

where $e(p, a)=1$ only if between $p$ and $a$ trips occur. Otherwise $e(p, a)=0$.

The origin of trip in the system is the users of the analysed area:

- Residents of the area travelling within the boundaries of the analysed area (internal trips);

- Residents of the area travelling outside the boundaries of the analysed area (generated trips);

- Visitors supplying the analysed area with trips (absorbed trips);

- Travellers crossing the area, constituting the so-called crossing trips, unrelated to the analysed area but involving the use of the supply layer of the transport system.

The analytical procedures joining the two layers comprise a set of interdependent calculation principles reproducing transport phenomena occurring in the actual system. The calculation process is iterative and involves the following four steps:

1. Traffic generation;

2. Spatial distribution of the traffic;

3. Choice of transport mode to enable the system user to make the trip;

4. Definition of the routes using the supply layer of the system, between all pairs of origins and destinations.

Surveys and transport research conducted within the area of the analysed system provided the principal source of data which enabled determination of the parameters of individual analytical procedures and formed the basis for verification of the approach and results for the transport model. Table 1 presents the data concerning the assessment of the applied transport model for the simulation.

Table 1. Data for assessment of the applied transport model for the simulation

\begin{tabular}{|c|c|c|c|}
\hline \multirow{2}{*}{ Parameter description } & \multicolumn{3}{|c|}{ Value } \\
\hline & Overall & Individual transport & Public transport \\
\hline Number of surveyed respondents & 494 & & \\
\hline Number of monitoring points & 17 & 58 & 121 \\
\hline $\begin{array}{l}\text { Percentage of elements meeting } \\
\text { the requirements of GEH statistic }\end{array}$ & 0.9 & 0.96 & 0.92 \\
\hline
\end{tabular}

\section{Basic assumptions for the analyses}

Table 2 presents the description of the transport network within the analysed test system. Figure 2 provides a graphic representation of the area.

Table 2. Description of the transport network of the analysed area

\begin{tabular}{|l|c|c|r}
\hline \multirow{2}{*}{ Parameter description } & \multicolumn{3}{c}{ Value } \\
\cline { 2 - 4 } & Overall & Individual transport & Public transport \\
\hline Number of traffic zones & \multicolumn{3}{c}{967} \\
\hline Total network length $[\mathrm{km}]$ & \multicolumn{3}{|c}{435.0} \\
\hline Number of nodes & \multicolumn{3}{c}{1121} \\
\hline Number of stops & \multicolumn{3}{c}{78} \\
\hline Number of lines & \multicolumn{3}{|c}{} \\
\hline
\end{tabular}




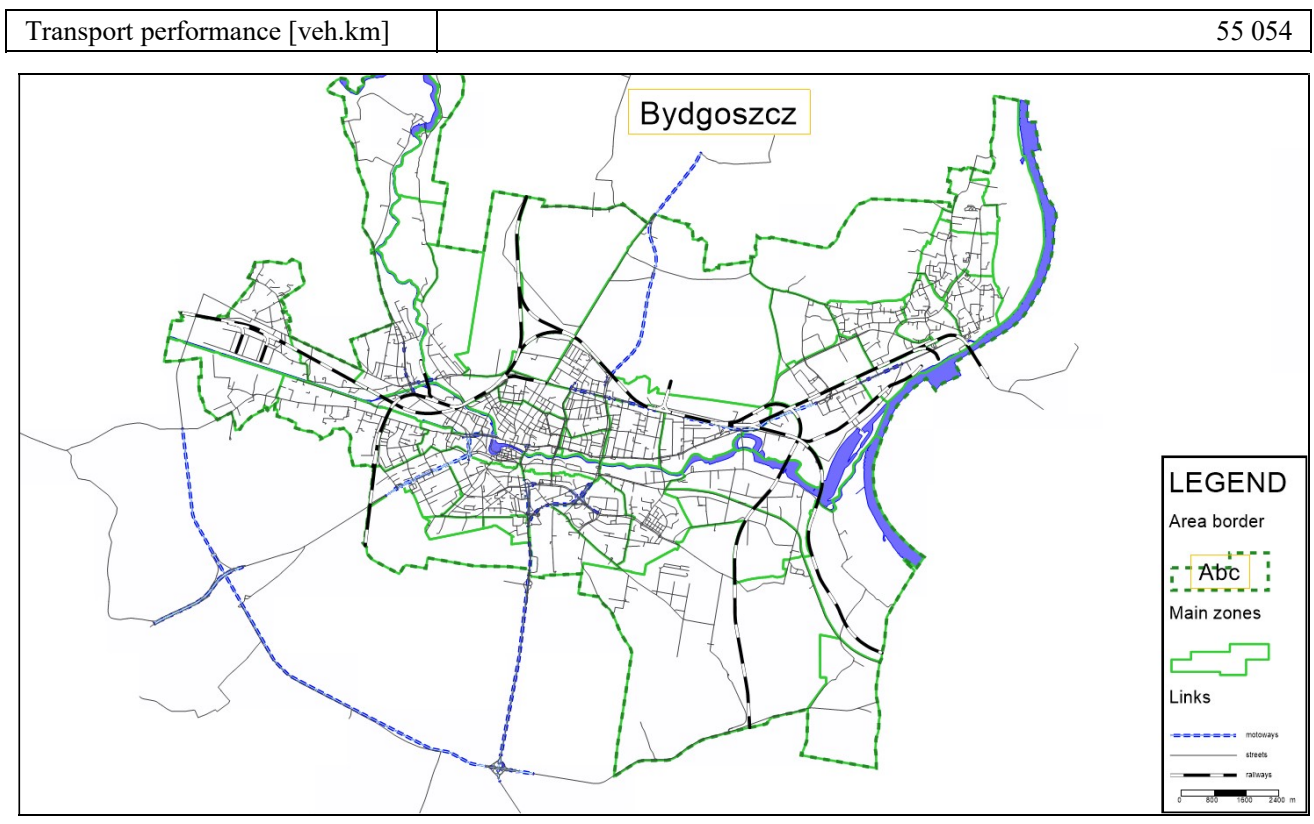

Fig. 2. Area of the test system

According to the description of the area the $35 \%$ share of green spaces and approximately $19 \%$ of farmland means that - in theory - more than half of the area comprises land which can be assigned as residential areas. The zoning plans developed by the local authorities in charge of spatial management - considering the need to offer locations which will be competitive to the suburbs - provide for measures to develop some of the land if it is in a close proximity of a forest, wood or river.

In order to determine potential effects of such measures and to find more efficient ways of spatial management of the city, the following four research scenarios were considered:

1. Initial condition ( $\mathrm{S} 0)$ - the baseline, where the extent of spatial development of the analysed area is not altered, i.e. is the same as in 2016;

2. Expansive actions (S1), involving the development of the land (hardly developed at present) situated on the boundaries of the area according to the plans of the local authorities; it has been assumed that - according to the spatial development plans - about 8,000 new households will be established in the new area; additionally, the required supporting infrastructure will be provided, including new roads, shops, schools, workplaces etc., and the public transport system will be modified to serve the new residential areas;

3. Sustainable actions (S2), involving the location of the same number of new households as in S1, but in the intermediate zone [9], which will not require huge investment in transport or extension of the supporting infrastructure (no changes to the transport systems are envisaged);

4. Centralising actions (S3), where the new households will be located in the central zone [9]; similarly to S2, the well-developed existing infrastructure does not require substantial investment in transport or extension of the supporting infrastructure (no changes to the transport systems are envisaged).

The location of new residential areas for the scenarios above is shown in Fig. 3.

It should be underlined that the research conducted for all the scenarios applies to the same total number of generated trips within the whole computing system. The key difference between individual scenarios mainly concerns the spatial location of the trip 
origins, and thus the spatial variability of the demand layer. It was assumed that the residents of the new households will come from the other parts of the city, and their share will be proportional to the residential density of the particular traffic zones.

The viability of implementation was verified for all the scenarios. According to the inventory taken by the authors, there are appropriate reserves of space in individual areas (the central zone, the intermediate zone and the surrounding zone) which make the scenarios assumed in modelling feasible. This particularly applies to the central zone (S3) in which ample reserves of space are available which enable the location of attractive residential estates.

Pollution emissions were calculated according to the guidelines of the Swiss Federal Office for the Environment (parameters based on 2000 revision guidelines) [7], and noise pollution was determined according to German standards, RLS 90 model [8]. In the models considered above, the emissions of chemicals and noise are caused by road traffic volumes, share of heavy goods vehicles (of $2.8 \mathrm{t}$ and more), vehicle speed at a given intensity of traffic, speed limits, type of roadway surface and grade. Regarding the noise, its level is expressed in $\mathrm{dB}$ as perceived at a distance of $25 \mathrm{~m}$ from the road centre line and a height of $4 \mathrm{~m}$ in the place of potential development.

Due to a lack of details regarding the structure of the fleet of vehicles, i.e. the share of vehicles powered by different propulsion systems (petrol, diesel oil, gas, electrical etc.), the analysis of carbon dioxide emissions was not performed. Considering that this kind of emission is strictly connected with the transport performance (number of kilometres driven by the vehicles) [10], the parameter was taken into account in analysis.

\section{Results}

The results of simulations developed for the assumed scenarios are summarised in the form of absolute values and percentages (relative to the baseline scenario, S0) in Table 4. The data concerns trips made by the users of the analysed area by public transport and private vehicles. It should be noted that the simulations comprise the other forms of travel, i.e. walking and cycling, as well. As a consequence, changes in the total number of trips effected by public transport and private vehicles mean that the modal division among all the trips (whether they generated emissions or not) was also changed.

Due to a considerable scatter of the travel origins in S1 scenario, the total number of all non-walking (and non-cycling) trips by $0.7 \%$ as compared to S0, which is contrary to S2 and S3 in particular, where a shorter distance between the origin and the destination justifies giving up $0.80 \%$ of all non-walking trips (which is nearly 6,000 trips, half of which made in private vehicles). This translates into a considerable increase in the transport performance in $\mathrm{S} 1$, reaching almost $2.2 \%$, and a reduction in this performance by $1.1 \%$ in $\mathrm{S} 2$ and by $1.4 \%$ in $\mathrm{S} 3$; however these changes apply to the public transport in particular $(+4.8 \%$ in $\mathrm{S} 1$, but $-2.3 \%$ and $-2.8 \%$ in $\mathrm{S} 2$ and $\mathrm{S} 3$, respectively). The changes are directly correlated with the change (extension or reduction) in the average travel length $(+1.5 \%$ in $\mathrm{S} 1$ and $-0.5 \%$ in $\mathrm{S} 2$ and $\mathrm{S} 3$ ) and time ( $+2 \%$ in $\mathrm{S} 1$ and $-1 \%$ in $\mathrm{S} 2$ and $\mathrm{S} 3)$.

These performance figures directly translate into the results of calculated emissions of harmful chemical substances, including carbon oxide (an increase by $2 \%$ in $\mathrm{S} 1$ and a decrease by $1.5 \%$ and $1.1 \%$ in S3 and S2, respectively). Only as regards noise emissions was a slight increase in the mean value for all the scenarios observed. However, the increase did not exceed $1 \%$, with the average noise level at about $70.6 \mathrm{~dB}$, which is equivalent of a loud conversation or the noise of a working vacuum cleaner in a closed room [11]. 


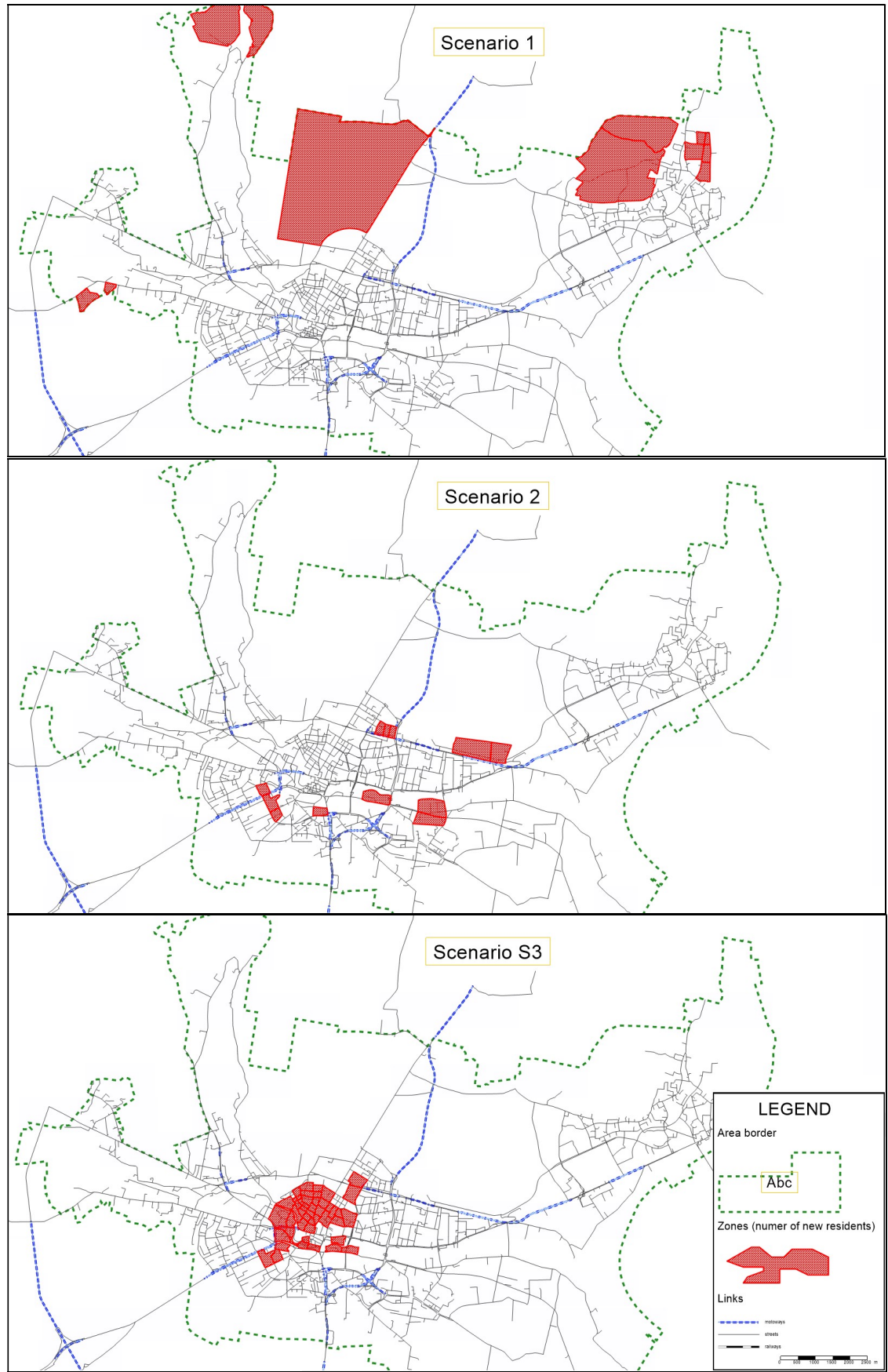

Fig. 3. Location of new residential areas for the individual scenarios. 
Table 4. Results of calculations for the individual scenarios of the analysis

\begin{tabular}{|c|c|c|c|c|c|c|c|}
\hline \multirow{3}{*}{ Parameter description } & \multicolumn{7}{|c|}{$\begin{array}{l}\text { Value for the specific scenarios } \\
\text { ( } 24 \mathrm{~h} \text {, workday) }\end{array}$} \\
\hline & \multirow{2}{*}{$\frac{\text { So }}{\text { value }}$} & \multicolumn{2}{|c|}{ S1 } & \multicolumn{2}{|c|}{ S2 } & \multicolumn{2}{|c|}{ S3 } \\
\hline & & value & $\% 0^{1)}$ & value & $\%{ }^{1)}$ & value & $\%{ }^{1)}$ \\
\hline \multicolumn{8}{|l|}{ Supply } \\
\hline $\begin{array}{l}\text { Length of transport network } \\
{[\mathrm{km}]}\end{array}$ & 922.0 & 935.1 & 1.42 & 922.0 & 0.00 & 922.0 & 0.00 \\
\hline $\begin{array}{l}\text { Transport performance TP } \\
\text { [veh-km] }\end{array}$ & 55054.22 & 55254.08 & 0.36 & 55054.22 & 0.00 & 55054.22 & 0.00 \\
\hline \multicolumn{8}{|l|}{ Demand } \\
\hline Number of trips $\left(\mathrm{TP}^{2)}+\mathrm{TI}^{33}\right)$ & 728273 & 733284 & 0.69 & 725148 & -0.43 & 722425 & -0.80 \\
\hline \multirow{2}{*}{ Number of trips TP/TI } & 238478 & 241080 & 1.09 & 236512 & -0.82 & 235591 & -1.21 \\
\hline & 489795 & 492205 & 0.49 & 488635 & -0.24 & 486835 & -0.60 \\
\hline \multicolumn{8}{|l|}{ Functional values } \\
\hline $\begin{array}{l}\text { Transport performance TP+TI } \\
\text { [veh-km] }\end{array}$ & 7695678 & 7863045 & 2.17 & 7615090 & -1.05 & 7591169 & -1.36 \\
\hline \multirow{2}{*}{$\begin{array}{l}\text { Transport performance TP/TI } \\
\text { [veh-km] }\end{array}$} & 1504779 & 1577510 & 4.83 & 1471276 & -2.23 & 1462612 & -2.80 \\
\hline & 6190900 & 6285535 & 1.53 & 6143814 & -0.76 & 6128556 & -1.01 \\
\hline Average travel speed $[\mathrm{km} / \mathrm{h}]$ & 35.7 & 35.53 & -0.46 & 35.80 & 0.30 & 35.85 & 0.45 \\
\hline \multirow{2}{*}{$\begin{array}{l}\text { Average travel speed TP/TI } \\
{[\mathrm{km} / \mathrm{h}]}\end{array}$} & 27.2 & 27.36 & 0.42 & 27.16 & -0.33 & 27.14 & -0.37 \\
\hline & 38.6 & 38.41 & -0.50 & 38.75 & 0.40 & 38.82 & 0.58 \\
\hline Average travel time $[\mathrm{h}]$ & 17.8 & 18.11 & 1.94 & 17.60 & -0.92 & 17.59 & -1.00 \\
\hline \multirow{2}{*}{$\begin{array}{l}\text { Average travel time TP/TI } \\
{[\mathrm{h}]}\end{array}$} & 13.9 & 14.35 & 3.27 & 13.74 & -1.09 & 13.72 & -1.25 \\
\hline & 19.6 & 19.95 & 1.54 & 19.47 & -0.92 & 19.46 & -0.98 \\
\hline $\begin{array}{l}\text { Average distance travelled } \\
{[\mathrm{km}]}\end{array}$ & 10.57 & 10.72 & 1.48 & 10.50 & -0.62 & 10.51 & -0.56 \\
\hline \multirow{2}{*}{$\begin{array}{l}\text { Average distance travelled } \\
\text { TP/TI }[\mathrm{km}]\end{array}$} & 6.31 & 6.54 & 3.70 & 6.22 & -1.41 & 6.21 & -1.61 \\
\hline & 12.64 & 12.77 & 1.03 & 12.57 & -0.52 & 12.59 & -0.41 \\
\hline \multicolumn{8}{|l|}{ Environmental impact } \\
\hline $\begin{array}{l}\mathrm{CO} \\
\text { (carbon monoxide in } \mathrm{kg} \text { ) }\end{array}$ & 4979.0 & 5081.3 & 2.06 & 4924.5 & -1.09 & 4906.7 & -1.45 \\
\hline HC (Hydrocarbons in kg) & 1754 & 1783.0 & 1.64 & 1743.1 & -0.64 & 1739.7 & -0.83 \\
\hline NOx (Nitric oxides in kg) & 4537 & 4589.5 & 1.15 & 4516.8 & -0.45 & 4511.8 & -0.56 \\
\hline SO2 (Sulphur dioxide in kg) & 448.0 & 454.2 & 1.39 & 445.2 & -0.61 & 444.5 & -0.78 \\
\hline $\begin{array}{l}\text { Average noise level /standard } \\
\text { deviation }[\mathrm{dB}]\end{array}$ & $\begin{array}{r}70.58 \\
7.19 \\
\end{array}$ & $\begin{array}{r}70.59 \\
7.16 \\
\end{array}$ & 0.01 & $\begin{array}{r}70.62 \\
7.13 \\
\end{array}$ & 0.06 & $\begin{array}{r}70.64 \\
7.13 \\
\end{array}$ & 0.09 \\
\hline $\begin{array}{ll}\text { 1) } & \text { percentage differenc } \\
\text { 2) } & \mathrm{TP} \text { - public transpo } \\
\text { 3) } & \mathrm{TI} \text { - individual vehi }\end{array}$ & $\begin{array}{l}\text { elative to th } \\
\text { transport }\end{array}$ & iitial condi & (S0 s & nario) & & & \\
\hline
\end{tabular}

The data collected in the table concerns a typical workday, and when the values are multiplied by 300 conversion days [12,13], annual results can be more or less determined. This is particularly applicable to the toxic emissions from road traffic, for which the annual values were significantly different for the individual scenarios of spatial management. For example, in $\mathrm{S} 1$ scenario the $\mathrm{CO}$ emission increased by nearly 30.7 tons a year, whereas in $\mathrm{S} 2$ and $\mathrm{S} 3$ it drops by $16.3 \mathrm{t}$ and $21.7 \mathrm{t}$, respectively. 


\section{Conclusions}

The analysis results presented in this paper clearly indicate a substantial influence the spatial management of a city has on the emissions of harmful chemical pollution generated by road traffic. The results also demonstrated that a policy of spatial management of an urban area which promotes new residential locations far from the city centre and attractive to settlers actually leads to increased air pollution throughout the city. The increased dispersion of residential housing forces the residents to travel more, longer and further, which is not possible by walking or cycling. Thus an improvement of living conditions of a selected group of residents settling in areas which are quite distant from the centre, contributes to the deterioration of environmental standards and, therefore, living standards of the users of the entire area.

The obtained results suggest that a completely opposite policy would be much more beneficial: undertaking measures to increase the population density in central areas which provide good connections and are highly urbanised enables cutting down on some trips made by means of transport which generate emissions, and replace them with walking and cycling, which is also good for a general health of the residents.

As a direct benefit, this kind of approach to spatial management would yield a reduction in harmful chemical emissions but also in the time spent travelling and the number of kilometres travelled, cutting the overall costs of transportation. It should be stressed that Polish cities are not densely populated, so most of them offer a huge potential to implement the recommended direction of spatial management policy.

This article is of an exploratory nature. The underlying calculations were done for hypothetical scenarios in models based on the current situation. Considering the observed trends in motorisation in Poland [14], indicating continued and growing preference for own car travel, the effects described in the article should be much bigger in further analysis for the forecast years of 2020-2040, when the share of individual transport modes is expected to increase at the cost of public transport.

\section{References}

1. Kenourgios D., Padhi P. (2012), Emerging markets and financial crises: Regional, global, or isolated shocks?, "Journal of Multinational Financial Management", Vol. 22, nr 1-2.

2. Kamiński T., The influence of the economic crisis in Europe on the external policy of the European Union, The Natolin European Centre, Warsaw 2013

3. Van Acker V., Witlox F., Car ownership as a mediating variable in car travel behaviour research using a structural equation modelling approach to identify its dual relationship, Journal of Transport Geography, volume 18, 2010

4. Word bank Data, Fertility rate, total (births per woman), January 2018,

5. Johnson M., Field L.MM., Dudley L. Poston Jr., More Deaths Than Births: Subnational Natural Decrease in Europe and the United States; Population and Development Review, Volume 41, Issue 4 December 2015, Pages 651-680

6. Lewandowska-Gwarda K, Antczak E., Migracje wewnętrzne w polskich miastach analiza z wykorzystaniem przestrzennej dynamicznej metody przesunięć udziałów, Wydział Ekonomiczno-Socjologiczny, Uniwersytet Łódzki 2015

7. Federal Council (2015), Enviromnet Switzerland 2015, BBI, Publications distribution office, Bern

8. RLS, 1990. Richtlinien für den Lärmschutz an Strassen. BM für Verkehr, Bonn, 1990. 
9. Burgess E W. The growth of the city. In: Park R E, Burgess E W, Mckenzie R D. The City. Chicago: University of Chicago Press, 1925, 47-62.

10. Ribeiro SK, Balassiano R. CO2 emissions from passenger transport in Rio de Janeiro. Transport Pol. 1997;4:135-139. doi: 10.1016/S0967-070X(97)00003-6

11. Clasy H., Clay's Handbook of Environmental Health, Routledge, 21st Edition 2017

12. JASPERS, "Blue Book - Road Infrastructure", European Commision, pp. 26-28, 2015.

13. JASPERS, Appraisal Guidance (Transport), The Use of Transport Models in Transport Planning and Project Appraisal, April 2014

14. European Commission (2017), EU transport in figures, Statistical pocketbook 2017, European Commission, ISBN 978-92-79-62312-7. 